\title{
FORMAÇÃO DE FORMADORES: PARADIGMAS FORMATIVOS E SABERES PROFISSIONAIS
}

\author{
Liliane Campos Machado ${ }^{1}$ \\ https://orcid.org/0000-0001-7793-7350
}

Resumo: Trata-se de uma investigação que tem como objeto de pesquisa os paradigmas da formação de professores e os saberes necessários ao processo formativo. Objetivamos mapear os paradigmas da formação de professores e os saberes constituintes da profissão docente. A pesquisa constitui-se em um estudo de caso que articula os seguintes procedimentos metodológicos: pesquisa bibliográfica, entrevistas orais e temáticas, transcritas e textualizadas. Privilegiou-se a abordagem quali-quantitativa na perspectiva histórico-cultural. Os sujeitos, investigados, foram os professores formadores atuantes em curso de licenciatura em História e em Pedagogia. O estudo evidenciou uma multiplicidade de paradigmas de formação de professores, como estes constituíram identidades profissionais e como os professores colaboradores se apresentaram frente a estes paradigmas. Os paradigmas demandam saberes específicos e estes vêm de fontes variadas, destacando-se os saberes da experiência profissional docente, bem como as interfaces e relações entre o processo de formação, os saberes, as práticas docentes. Podemos afirmar que os formadores investigados possuem características constitutivas da profissionalidade dos formadores de professores.

Palavras-chave: educação; paradigmas da formação; formação de professores; saberes docentes.

${ }^{1}$ Doutorado em Educação pela Universidade Federal de Uberlândia. Professora da Faculdade de Educação da Universidade de Brasília (UnB). E-mail: Icmpedagogia@gmail.com. 
Machado, L. C.

\section{TEACHER EDUCATION: TRAINING PARADIGMS AND PROFESSIONAL KNOWLEDGE}

Abstract: This is an investigation that has as its object of research the paradigms of teacher education and the necessary knowledge for the formative process. We aimed to map the paradigms of teacher education and the knowledge needed for the teaching profession. The research is a case study that articulates the following methodological procedures: bibliographic research, oral and thematic interviews, transcribed and textualized. The qualiquantitative approach from the cultural-historical perspective was favored. The subjects investigated were teacher educators working in the undergraduate courses in History and Pedagogy. The study showed a multiplicity of paradigms of teacher education, how these paradigms constituted professional identities and how the collaborating teachers presented themselves facing these paradigms. The paradigms demand specific knowledge and this knowledge comes from various sources, especially the knowledge of the professional teaching experience, as well as the interfaces and relations between the training process, the knowledge, and the teaching practices. We can state that the investigated trainers possess constitutive characteristics of the professionalism of teacher trainers.

Keywords: education; training paradigms; teacher training; teacher knowledges.

\section{FORMACIÓN DE FORMADORES: PARADIGMAS DE FORMACIÓN Y CONOCIMIENTOS PROFESIONALES}

Resumen: Esta es una investigación que tiene como objeto de estudio los paradigmas de la formación docente y los conocimientos necesarios para el proceso formativo. El objetivo es trazar los paradigmas de la formación del profesorado y los conocimientos necesarios para la profesión docente. La investigación es un estudio de caso que articula los siguientes procedimientos metodológicos: investigación bibliográfica, entrevistas orales y temáticas, transcritas y textualizadas. Se privilegió el enfoque cuali-cuantitativo en la perspectiva histórico-cultural. Los sujetos investigados fueron los profesores de formación que actuaban en el curso de graduación en Historia y Pedagogía. El estudio evidenció una multiplicidad de paradigmas de formación de los profesores, cómo constituían las identidades profesionales y cómo se presentaban los profesores colaboradores frente a estos paradigmas. Los paradigmas exigen conocimientos específicos y éstos provienen de diversas fuentes, destacando el conocimiento de la experiencia profesional docente, así como las interfaces y relaciones entre el proceso de formación, los conocimientos y las prácticas docentes. Podemos afirmar que los formadores investigados poseen características constitutivas de la profesionalidad de los formadores de profesores.

Palabras clave: educación; paradigmas de formación; formación del profesorado; conocimientos del profesorado. 


\section{Introdução}

A discussão sobre formação e saberes docentes, no debate acadêmico, ganha destaque no Brasil, particularmente, a partir das décadas de 1980 e 1990, influenciada pelo contexto internacional de investigações educacionais. Tardif (2000) declara que, dentre alguns dos motivos que contribuíram para emergência do debate, está o movimento de profissionalização do ensino e também suas consequências para a questão do conhecimento dos professores na busca de um repertório de conhecimentos, visando a garantir a legitimidade da profissão, havendo, a partir daí, uma ampliação tanto quantitativa quanto qualitativa desse campo.

Intencionamos, com a pesquisa, mapear os paradigmas da formação de professores e os saberes docentes constituintes da identidade profissional docente.

O caminho metodológico adotado privilegiou a abordagem quanti-qualitativa e optamos, também, pelo uso de fontes orais, inspirados na vertente da história oral temática (BOM MEIHY, 2002). Assim, a metodologia combinou os seguintes procedimentos de investigação: pesquisa bibliográfica e estudo de caso por meio entrevistas orais temáticas, transcritas e textualizadas. Os sujeitos colaboradores foram professores do curso de Licenciatura em História e Pedagogia de instituição pública de ensino superior.

Quando se discute a formação docente em todos os níveis de ensino, não se deve deixar de questionar o que significa ser professor em tempos marcados pela transitoriedade dos discursos e pela desconstrução de uma imagem social de escola e da profissionalidade docente, sobretudo, a partir do momento em que se deslegitima a educação como um direito sociocultural, que passa a ser promovida como um produto de mercado. Nessa lógica organizamos este artigo discutindo os paradigmas da formação de professores e saberes necessários a constituição de uma identidade profissional docente.

\section{Paradigmas da Formação de Professores}

No debate acadêmico brasileiro, influenciado pelo contexto internacional, ganha destaque na discussão os "modelos" ou paradigmas de formação. Pereira (2006) evidencia que a formação de professores no Brasil, nos anos de 1970, caracterizou-se pelo treinamento de técnicos em educação oriundos do paradigma da "racionalidade técnica". 
A racionalidade técnica é uma perspectiva de formação herdada do Positivismo, que se consolidou fortemente no Brasil a partir dos anos de 1960 e que supunha a atividade educativa como uma aplicação rigorosa de princípios e leis gerados na investigação científica. Trata-se de um enfoque linear entre processo e produto, no qual logra importância vital a correlação entre os padrões de comportamento do professor ao ensinar (processo/variável independente) e o rendimento acadêmico dos alunos (produto/variável dependente) (GÓMEZ, 1998). Nessa perspectiva, para Candau (1998, p. 20), "o professor era concebido como um organizador dos componentes do processo de ensino-aprendizagem (...) que deveriam ser rigorosamente planejados".

Uma das professoras entrevistadas formou-se nesse contexto e relata:

\begin{abstract}
Meu curso de Pedagogia foi muito generalista, mas, nos dois últimos anos (1969-1970), sofreu algumas transformações. Nos primeiros anos, fizemos as disciplinas da Licenciatura e, no último, as disciplinas voltadas para a área de administração. Em função da transição, apesar de o curso ser noturno, as aulas iniciavam-se à tarde, pois nós tínhamos seis horários. A carga horária tinha como objetivo suprir a questão generalista. Essa transição se deu em função das habilitações e das condições impostas pela Lei 5540/68, que reformulou o Ensino Superior do país. (Professor H - Pedagogia)
\end{abstract}

Não é difícil perceber as razões das críticas dirigidas à perspectiva de formação profissional inspirada no modelo "racional-técnico". Ao mesmo tempo em que ignora teoria e prática como categorias inter-relacionadas e em permanente movimento dialético na práxis humana, o paradigma da racionalidade técnica escamoteia os fins sociais, morais e políticos da ação profissional. Tal situação no Brasil contribuiu para a perda de prestígio da profissão docente, o que se refletiu na baixa procura pelos cursos de formação de professores, na baixa remuneração dos profissionais (ou semiprofissionais) do ensino, na baixa-estima da maioria dos professores. (GAMBOA, 1995)

Trata-se de uma perspectiva de formação determinística, acrítica, situando o(a) professor(a) como técnico que dissemina conhecimentos. Parece que os modelos formativos fundamentados nessa concepção não dão conta das necessidades formativas dos(as) professores(as). Na pesquisa realizada, observamos que os professores 
formadores, principalmente do curso de Pedagogia, formaram-se nesse paradigma, como pode-se observar nas narrativas a seguir.

(...) na graduação, fui influenciada pelo tecnicismo, e nós tínhamos uma prática muito tecnicista (..) (Professor M - Pedagogia)

“(...) foi um curso muito teórico e muito tecnicista, mas teve pontos positivos" (Professor A - Pedagogia)

Na década de 1980, iniciava-se, entre nós, o debate sobre a configuração de um novo paradigma para a formação de professores, que é apresentado por Pereira (2006, p. 17) como:

(...) movimento de rejeição à visão de educação e de formação de professores, predominante na época, ganha força. A tecnologia educacional passou a ser fortemente questionada pela crítica de cunho marxista. Essa tendência reagiu violentamente à forma neutra, isolada e desvinculada de aspectos político-sociais, pelo qual a formação docente foi, fundamentalmente, tratada até a década anterior.

Nos primeiros anos da década de 1980, o foco voltou-se para: "o caráter político da prática pedagógica" e o "compromisso do educador com as classes populares" (SANTOS, 1992, p. 139)

Destacamos, entre os formadores entrevistados e que se formaram naquela década, a narrativa do Professor D (Pedagogia), quando ele alega que: "a minha qualificação foi se dando no movimento, dentro das minhas atividades, o movimento social, o movimento negro, as atividades de greves dos meus professores de faculdade".

Pereira (2006) faz alusão a essa época como uma década marcada por várias reflexões sobre a formação de professores, tais como: as várias críticas ao sistema de ensino brasileiro, inserido no contexto de uma sociedade capitalista dependente; a descaracterização e a desvalorização como eixo central da problemática do magistério como profissão.

Dessa forma, o educador deveria ser formado sob dois aspectos distintos e indissociáveis: a competência técnica e o compromisso político. Candau (2004) afirma que que a questão da competência técnica era condição necessária para o educador assumir um compromisso político. Todavia, esse foi um dos pontos não consensuais da discussão. Surge assim, em meados da década de oitenta, uma discussão sobre a importância de trabalhar a teoria e prática de forma vinculada e, também, sobre o papel da universidade na formação de professores (PEREIRA, 2006). 
Com o findar da década de oitenta e com as mudanças ocorridas no cenário internacional, no que se refere as políticas educacionais e à formação de professores, vivenciamos, intensamente, nos anos de 1990 nas Ciências Sociais e na Educação, uma crise de paradigmas. Isso desencadeou, no pensamento educacional brasileiro e nos estudos sobre a formação e os saberes de professores, "uma compreensão dos aspectos microssociais, destacando e focalizando, sobre novos prismas, o papel do agente-sujeito". (PEREIRA, 2006, p. 41).

Autores, estudiosos da formação de professores, nos anos noventa, indicavam como fundamento da atividade docente a articulação entre teorias e práticas, configurando o movimento que foi denominado de epistemologia da prática (PIMENTA, 1997; TARDIF, 2000). Entendendo que a mediação entre pesquisa educacional e ação reflexiva docente é a base da nova epistemologia da prática, pois o profissional não pode constituir seu saber fazer a não ser a partir de seu próprio fazer. Não é senão sobre essa base que o saber (docente), como elaboração teórica, se constitui (PIMENTA, 1999). A epistemologia da prática coloca em pauta a identidade do professor como pesquisador produtor de saberes. Um sujeito mergulhado na cultura pedagógica e institucional da escola, construindo, assim, sua identidade profissional.

Nas discussões efetuadas pelos autores, percebemos que o paradigma do "professor pesquisador" está muito associado ao de "professor reflexivo", desde as proposições de Schön (2000), baseadas nas ideias de "conhecer na ação", "reflexão na ação" e "reflexão sobre a reflexão na ação". Pimenta (2002, p. 20) assegura que é o movimento representado pela "reflexão sobre a reflexão na ação" que "abre perspectivas para a valorização da pesquisa na ação dos profissionais, colocando as bases para o que se convencionou denominar o professor pesquisador de sua prática".

Moraes e Torriglia (2003), ao discutirem a configuração contextual desse novo paradigma de formação de professores (professor pesquisador-reflexivo), evidenciam o risco das práticas centradas em si mesmas, circunscritas somente ao espaço escolar. Para as autoras, as práticas de formação de professores, embora possam e devam estar diretamente articuladas às vivências da docência, carecem da fundamentação das teorias pedagógico/educacionais em estreito diálogo com as ciências sociais e humanas.

Nesse contexto, está a crítica ao intelectualismo acadêmico - que distancia a Universidade dos processos que ocorrem na escola e na prática educativa, enredada no 
discurso da profissionalização, mas, ao mesmo tempo, está o que Shiroma (2003) vem denunciar como um processo de "desintelectualização" do professor, ratificado pelas políticas de reforma educacional.

Discutir sobre formação de professores significa refletir sobre a necessidade de articulação entre teoria e prática, compreendendo a trajetória profissional como possibilitadora de aprendizagens sobre a profissão. Representa entender que a experiência docente se configura como importante elemento no processo de desenvolvimento pessoal e profissional do(a) professor(a). No entanto, a esse respeito, Guarnieri (2000) nos alerta que esses pressupostos não são suficientes para evitar a unilateralidade e os reducionismos sempre presentes quando se trata a questão da formação do professor, ora dando-se excessivo peso ao conhecimento teórico-acadêmico, ora às questões postas pela prática pedagógica.

Percebemos, com as reflexões feitas sobre o "professor pesquisador", e sobre o "professor reflexivo", que são nomes distintos, maneiras diferentes dos teóricos abordarem uma mesma realidade. O professor pesquisador é aquele que pesquisa, produz saberes ou que reflete sobre a sua prática. O professor reflexivo o concebemos um professor indagador, que pensa sua própria realidade escolar (experiência) como um objeto de pesquisa, como objeto de reflexão e de análise. No entanto a experiência, por si só, não é formadora. Podendo inclusive ser uma mera repetição, uma mera rotina, não é ela que é formadora. Formadora é a reflexão sobre essa experiência, a pesquisa e a produção de saberes sobre a transmissão de experiência. (MACHADO, 2009, p. 141)

A construção da identidade de professor formador, ao longo de sua formação, como profissional reflexivo, é uma dimensão que tem sido defendida e valorizada por vários pesquisadores, dentre eles, Zeichner (1992), que aponta alguns fatores que contribuíram para a construção desse conceito de professor reflexivo. O primeiro aspecto a ser destacado é o professor como agente ativo e responsável pelos rumos do seu trabalho docente, em oposição ao mero executor de tarefas definidas por outros. O segundo a considerar são os saberes tácitos dos professores, não apenas os saberes acadêmicos como válidos e, por último, reconhecer a construção da prática do professor como um processo contínuo a ser aprimorado no decorrer de sua vida.

Concordamos com o autor que a reflexão é uma ação que se dá espontaneamente a partir de uma situação problemática, considerando os sentimentos/emoções como 
fatores que permeiam as atitudes dos professores, opondo-se, assim, à atitudes preestabelecidas tecnicamente.

O autor considera que uma das formas do professor assumir uma postura reflexiva deve ser por meio da socialização, com seus pares, das teorias práticas do professor e que estes percebam quais são as condições sociais que "modelam" as suas experiências de ensino. Sobre isto vejamos a narrativa de um formador colaborador "Como professor, temos que dar conta do espaço da sala de aula, de atribuir ao conteúdo valor significativo para que isso contribua com a formação do acadêmico e que essa consiga promover o desenvolvimento do sujeito social." (Professor E - Pedagogia)

Fazendo uma leitura das críticas de Zeichner (1992) a Schön (2000), Pimenta (2002, p. 23) argumenta que:

(...) A intervenção reflexiva proposta por Schön, a partir de Dewey, é uma forma de sustentar a incoerência em se identificar o conceito que o professor reflexivo com práticas ou treinamentos que possam ser consumidos por um pacote a ser aplicado tecnicamente, (...) gerando uma massificação do termo 'reflexivo', o que dificulta uma atitude crítica do professor.

A respeito da possibilidade de uma efetiva atitude reflexiva por parte dos professores, é necessário considerar dois aspectos apontados por Pimenta (2002). primeiro diz respeito ao papel da teoria, o segundo refere-se à reflexão coletiva. A autora se posiciona a partir dos estudos de Sacristan (1998), quando o autor declara que "Somos reflexivos, porque adquirimos consciência do que fazemos. Afetamos não só o que ocorre fora do mundo, como também o que fazemos" (ibid., p.50), e "a reflexibilidade é apresentada como o exercício da razão no esclarecimento dos fins e dos desejos pessoais e coletivos para avaliá-los e decidir a favor de um determinado compromisso (ibid., p.45).

Percebendo os limites do movimento de reflexão proposto por Schön (2000), Pimenta (2002), descreve, pelas preocupações de Giroux (1990), que sua concepção de professor como intelectual crítico caracteriza-se por atribuir a reflexão como coletiva, desenvolvendo uma análise dos contextos escolares aos contextos mais amplos, que extrapolam os limites da escola, tendo clara a direção de sentido da reflexão. Nessa perspectiva, a autoridade de transformação conferida ao professor não se caracteriza somente no nível individual, mas também lhe confere autoridade pública para realizá-la. É 
importante envolver, nesse processo, diversos setores competentes nos aspectos educativos, como a universidade?2.

Contreras (1997) evidencia um alargamento na discussão de temas sobre o trabalho docente, as organizações escolares, os sistemas de ensino e a formação inicial e continuada dos professores, e discussões pautadas em temas como a gestão, o tempo de ensinar, os currículos, o projeto político pedagógico, a identidade e os saberes do professor e a sua autonomia. Em uma análise da perspectiva crítica de Giroux (1997), Contreras (1997) alerta para o risco de sua teoria se limitar ao discurso, pois não se sustenta na análise das condições da escola, não oferece uma análise das mediações que possibilitem sua efetivação. Considerando que a escola não é homogênea e os professores são sujeitos ativos, é oportuno analisar como ocorre o processo entre os interesses dos professores, e os valores e conflitos os quais a escola representa.

Segundo Giroux (1997), muitos são os desafios e as ameaças no campo educacional. Ameaças no que concerne às reformas educacionais que não consideram o professor como uma liderança intelectual na escola. As reformas educacionais consideram o professor, segundo o autor, apenas como um executor das propostas que são pensadas por especialistas. Dessa forma, o autor sugere, aos professores, engajarem-se num debate político mais amplo, compreendendo a educação como um ato político. Para isso, os professores devem repensar a sua função. Além disso, torna-se imprescindível o debate coletivo com seus pares.

Propõe, então, que a natureza da atividade docente seja vista e repensada e que os professores sejam intelectuais transformadores, os quais devem estar atentos às condições materiais, ideológicas e políticas que condicionam a sua prática docente, assumindo uma postura crítica diante dos fatos da realidade, assumindo, também, um papel ativo em relação ao planejamento, avaliação, seleção dos conteúdos, as metodologias mais adequadas, com o intuito de redimensionar sempre a sua prática a favor da aprendizagem de seus educandos. A respeito vejamos as narrativas de um formador

Eu procuro ser assim, seguir a ementa, a referência bibliográfica, atualizar a minha referência bibliográfica, mas eu gosto muito de trabalhar aquilo que eu penso, Eu acho que é $50 \%$ o que a instituição

\footnotetext{
2 Sobre esse assunto ver Paim (2005), Alves (2008), Miglio (1999), Andrade (2001) dentre outras dissertações e teses defendidas no Brasil.
} 
quer o que o sistema quer e $50 \%$ o que eu quero o que eu acredito que está a favor do aluno. (Professor B - História)

Giroux (1997) julga os professores intelectuais transformadores em uma perspectiva em que se torna fundamental repensar e reestruturar a natureza da atividade docente. $\mathrm{O}$ professor, como intelectual crítico, deve ser capaz de compreender os fatores sociais e institucionais que regulam a sua prática educativa, para tanto, deverá ter a responsabilidade de desvendar o oculto e a origem histórica e social dos fatos que se apresentam, percebendo os disfarces que há por trás de discursos e programas que defendem a teoria crítica, como pontua Ghedin:

\begin{abstract}
A figura do intelectual crítico é, assim, a de um profissional que participa ativamente no esforço por desvelar o oculto, por desentranhar a origem histórica e social do que se apresenta a nós como "natural", por conseguir captar e mostrar os processos pelos quais a prática de ensino atrapalha-se em pretensões, relações e experiências de duvidoso valor educativo. (GHEDIN, 2002, p.140)
\end{abstract}

Mesmo diante das dificuldades subjacentes ao processo de ensino e aprendizagem, não podemos nos esquecer de que é imprescindível, ao professor, de modo particular o professor formador no Ensino Superior, ultrapassar o status de simples executor para intelectual crítico. Sobre isso, narrou um docente: "acredito ter melhorado muito minha prática. A pesquisa me ajudou muito a refletir minha prática, já que parte dos sujeitos participantes dela eram meus alunos. Então pude-me "ver" através dos posicionamentos deles" (Professor R - História)

Segundo Pereira (2006) o debate acadêmico sobre a formação de professores, nas últimas quatro décadas, apresenta elementos de conservação e de mudança. Concordamos com o autor, ao acreditar que "a recorrência de alguns temas nos dá a impressão de estarmos discutindo os mesmos problemas, durante anos e mesmo décadas atrás, sem, no entanto, conseguirmos solucioná-los" (PEREIRA, 2006, p. 51).

A nosso ver, o professor (como pesquisador em sala de aula) passará a ser reconhecido como um profissional mais completo do que um pesquisador externo ao processo, pois, enquanto este último trabalha com fragmentos do objeto, aquele trabalha com o sujeito e o objeto em sua totalidade. Ou seja, cabe ao professor juntar, em sala de aula, todos os fragmentos produzidos pela pesquisa, agindo na urgência e decidindo na incerteza - como filosofa Perrenoud (PERRENOUD, 2001). 
As novas abordagens ${ }^{3}$ de pesquisa educacional passaram a reconhecer o professor como sujeito de um saber e de um fazer, reforçando a necessidade de investigar os saberes de referência dos professores, suas próprias ações e pensamentos. Para Silva (1997), a análise dos valores e princípios de ação que norteiam o trabalho dos professores pode trazer novas luzes sobre nossa compreensão acerca dos fundamentos do trabalho docente, no sentido de desvendar atitudes e práticas presentes no dia a dia das escolas que, historicamente, foram ignoradas pela literatura educacional (e talvez possam trazer contribuições para o trabalho e a formação de professores). A seguir abordamos os saberes necessários ao ser formador de formadores.

\section{Saberes necessários a formação profissional}

Considerando que a tessitura dos saberes docentes mobiliza saberes "por" e "para" competências docentes e considerando que a profissão de educador é uma construção subjetiva e contextualizada à realidade social e aos saberes legitimados pela sociedade, o profissional docente define-se ao assumir um ofício de saberes que, em sua legitimação, torna público um ofício privado o qual se constitui na identidade subjetiva construída, a partir da significação social que o docente retrata nas execuções das tarefas que lhe são próprias e estruturadas no cotidiano de seu trabalho, por se considerar o ensino como "um ofício universal" (GAUTHIER, 1998, p. 53).

Por essa razão, pensar em uma análise dos saberes nos remete à intersubjetividade, interagindo, historicamente, com a sociedade, o indivíduo, a ciência e a instituição de ensino. Dessa interação, configura-se uma identidade profissional, definida por práticas consagradas e culturalmente significativas. Segundo Roncato (2002), a identidade docente consubstancia-se pela mobilização de saberes, entendendo que estes encerram um projeto de ação ativando recursos administrativos, contextuais, técnicos, experienciais, pedagógicos e científicos. E que essa mobilização de saberes permite não incorrermos no erro de manter, a esse respeito, uma espécie de cegueira conceitual em que o ofício sem

\footnotetext{
3 O que denominamos "novas abordagens" da pesquisa educacional refere-se à temática dos saberes docentes e como estes têm se mostrado uma área um tanto recente, o que vem demandando estudos sob diferentes enfoques. A tendência que fundamenta essas novas abordagens são os estudos sobre saberes docentes que consideram a atuação do professor como questão central e passa a valorizar os processos de formação que dão "voz ao professor". Essa tendência na produção de pesquisa brasileira é influenciada pela literatura internacional especialmente por meio de autores como Nóvoa (2008), Hubermann (1992), Goodson (1995), Tardif (2000), dentre outros.
} 
saberes se manifesta por meio da crença de que basta conhecer o conteúdo, ter talento, ter experiência ou ter bom senso para se exercer eficazmente a docência. (GAUTHIER, 1998)

Para discutirmos os saberes da docência, buscamos, em Foucault, uma conceituação para o termo "saber", que segundo o autor, significa "(...) conjunto de elementos, formados de maneira regular por uma prática discursiva e que são indispensáveis à constituição de uma ciência, apesar de não se destinarem necessariamente a lhe dar lugar, pode-se chamar saber" (FOUCAULT, 1987, p. 222).

Para Burke (2003), há uma diferenciação entre os saberes. Para ele existe "uma distribuição espacial do conhecimento, dos lugares em que o conhecimento foi descoberto, guardado ou elaborado e difundido". Ainda, os conhecimentos têm origens diversificadas e, consequentemente, grupos dominantes produzem classificações diferenciadas diante de seu próprio entendimento. Corroborando Burke sobre a produção do conhecimento na contemporaneidade, propomo-nos a analisar a questão dos saberes docentes e como se estabelecem as relações entre saberes e a formação de professores formadores de professores.

Rodrigues (2009) assegura, há um conjunto de saberes imprescindíveis ao exercício profissional (saberes da especialidade de ensino e saberes da educação) que se devem e podem ser aprendidos independentemente da prática, isto é, saberes cuja apropriação pelos alunos-professores não exige uma aprendizagem situada ou sequer uma aprendizagem que dependa de interesses ou preocupações contextualizados numa prática

Segundo Gauthier (1998) ao pensarmos em modelos de formação de professor, devemos levar em conta o contexto no qual se constroem os saberes docentes, isto é, as condições históricas e sociais nas quais se exerce a profissão; condições que servem de base para a prática docente, pois o professor possui, em virtude da sua experiência de vida pessoal, saberes próprios, que são marcados por questões culturais e pessoais.

Nessa perspectiva, considerando a existência de um repertório de conhecimentos de ensino que envolve os saberes profissionais do próprio professor, Gauthier e Mellowki (2004, p. 553) nos dá uma contribuição importante ao analisar que "o saber docente pode ser definido a um só tempo como conjunto instituído de conhecimentos e de práticas 
relativas ao ofício de ensinar - ou seja, que tem como objetivo a instrução e a educação dos indivíduos (...)".

Nesse sentido, Tardif e Lessard (2000, p. 15) esclarecem que, "o saber docente é plural, estratégico e, muitas vezes, desvalorizado, constituindo-se em um amálgama, mais ou menos coerente, de saberes oriundos da formação profissional, dos saberes das disciplinas, dos currículos e da experiência".

O autor preocupa-se, particularmente, com os saberes mobilizados e empregados pelos professores em seu cotidiano. Saberes esses que se originam, de uma maneira ou de outra, da própria prática docente e que servem para resolver os problemas dos professores em exercício e para dar sentido às situações de trabalho com as quais convive diariamente (ibid., p. 39). Apropriando-se dessa concepção no contexto da formação e dos saberes dos formadores, evidenciamos:

O professor formador aponta caminhos a partir da experiência e dos estudos, orientando de forma satisfatória seus formandos, sob o olhar para o mercado de trabalho, enfim, para toda a realidade social do meio onde vive e realiza seu trabalho. Ele, antes de tudo, tem uma responsabilidade social. (Professor $\mathrm{R}$ - História)

Para Pimenta (1999), a mobilização dos 'saberes dos professores', referidos por ela como 'saberes da docência', é um passo importante para mediar o processo de construção da identidade profissional dos professores. Isso denota que esses saberes são constituídos por três categorias: os 'saberes da experiência', os 'saberes do conhecimento' - os da formação específica (Matemática, História, Artes e outros) e os 'saberes pedagógicos', aqui entendidos como os que viabilizam a ação do 'ensinar'. Neste prisma, para a autora, as três categorias identificam o que é necessário saber para ensinar.

Os saberes necessários ao ensino são reelaborados e construídos pelos professores "em confronto com suas experiências práticas, cotidianamente vivenciadas nos contextos escolares" (PIMENTA, 1999, p. 29) e, nesse confronto, há um processo coletivo de troca de experiências entre seus pares, o que permite que os professores, a partir de uma reflexão na prática e sobre a prática, possam constituir seus saberes necessários ao ensino.

Levando-se em conta o que foi observado, vale ressaltar que os saberes dos professores, aprendidos durante a formação inicial (saberes das disciplinas e saberes da formação profissional), serão reformulados e vão se reconstruindo no dia a dia da sala de 
aula a partir dos saberes curriculares e da experiência e de outros saberes científicos da formação continuada e do desenvolvimento profissional.

Com referência aos saberes que são construídos pelos professores em seu processo de formação inicial e continuada, Saviani (1996, p.47), ao se referir a eles, enuncia que configuram o trabalho do educador, noção que, para o autor, ultrapassa a de professor, visto que "o ato de produzir, direta e intencionalmente, em cada indivíduo singular, a humanidade que é produzida histórica e coletivamente pelo conjunto dos homens", constitui o trabalho educativo que é próprio do educador, afirma que, sendo o processo educativo um fenômeno complexo, os saberes nele envolvidos também o são. Por conseguinte, o autor identifica cinco categorias de 'saberes': o saber atitudinal, o saber crítico-contextual, os saberes específicos, o saber pedagógico e o saber didáticocurricular, entendendo que são estes os saberes que todo educador deve dominar e que, portanto, devem integrar o seu processo de formação.

Saviani (1996, p. 45) alerta para o fato de que o educador é aquele que educa, o qual, consequentemente, precisa saber educar, precisa aprender, precisa ser formado, precisa ser educado para ser educador, precisa dominar os saberes implicados na ação de educar. Sob essa ótica, o autor afirma que se invertem os termos da questão: "em lugar de os saberes determinarem a formação do educador, é a educação que determina os saberes que entram na formação do educador".

A afirmação de Saviani (1996) contribui para a premissa de que o professor/educador possui uma visão de mundo, uma concepção de educação, de ensino e que essas concepções determinam os tipos de saberes que deverão ser mobilizados numa determinada situação dentro e fora da sala de aula.

Tardif (1999) afirma que os saberes profissionais docentes são plurais e heterogêneos, pois trazem à tona conhecimentos e manifestações do saber-fazer e do saber-ser bastante diversificados, provenientes de diversas fontes. Portanto, a noção de saber deve englobar conhecimentos, saber-fazer e saber-ser, já que os professores, frequentemente, referem-se aos seus saberes de forma bem abrangente, referindo-se tanto ao conhecimento da matéria como ao conhecimento dos grandes princípios educacionais e dos sistemas de ensino.

Tardif (1999, p. 10) analisa a questão dos saberes profissionais e a sua relação na problemática da profissionalização do ensino e da formação de professores. Para ele, "se 
esses esforços e reformas forem bem-sucedidos o ensino deixará, então, de ser um ofício para tornar-se uma verdadeira profissão. Tardif (2000) entende que os fundamentos do ensino são, a um só tempo, existenciais, sociais e pragmáticos.

Philipe Perrenoud (1993) ressalta que o improviso, a multiplicidade de interações simultâneas e desconexas, a infinidade de pequenas decisões a serem tomadas com rapidez, sem reflexão; ele dá ênfase ao ensino como trabalho com pessoas, uma "profissão relacional", em que o principal "instrumento de trabalho" é a pessoa do professor, um sujeito em interação com outros sujeitos, uma atividade cujas dimensões sociais e afetivas não podem ser desconhecidas.

As narrativas dos professores formadores expressam dimensões de sua experiência de ensino.

(...) na semana passada, eu dei aula na Pós-Graduação e Willian ex aluno da graduação me disse:"eu vim pra cá assistir sua aula, mas eu não assisti". Perguntei: por quê? Porque eu vim com uma professora na cabeça e chegando aqui encontrei uma outra. (Professor B - História).

[...] na época em que eu trabalhei na Educação Básica, eu era uma professora recém-formada no Magistério, então, eu tinha aspirações totalmente diferentes. [...] na universidade, não é tanto esse tipo de exigência, a exigência é diferente. Se na Educação Básica a exigência é mais, física, vamos dizer assim, na universidade, é uma exigência mais intelectual, mais mental, há uma outra forma de exigência que é mais desgastante, até emocionalmente. (Professor G - Pedagogia).

Dubet e Martuccelli (1996) chamam a atenção para a dimensão relacional, e, para eles, os professores tendem a afirmar a superioridade da experiência sobre qualquer outra formação, porque é, sobretudo, face a face com a classe que eles constroem sua identidade.

A pluridimensionalidade do 'saber profissional' dos professores é referendada por Tardif e Gauthier (1996, p. 11), como “o saber docente é um saber composto de vários saberes oriundos de fontes diferentes e produzidos em contextos institucionais e profissionais variados". Sob este aspecto, Tardif, (1991, p. 218) nos mostra que "a relação dos docentes com os saberes não se reduz a uma função de transmissão dos conhecimentos já constituídos, pois sua prática integra diferentes saberes, com os quais o corpo docente mantém diferentes relações". E para darem conta dos objetivos traçados, os professores comumente utilizam: os saberes das disciplinas, os saberes curriculares, os 
saberes da formação profissional e os saberes da experiência. Desse modo, essa mescla de saberes, para Tardif (1991) constitui, possivelmente, o que é necessário saber para ser um formador de formador.

\section{Algumas considerações...}

Em suma, ousamos afirmar que a profissão de professor se aprende na sociedade, na escola e na sala de aula, e que é um processo longo. Porém, há um conjunto de saberes imprescindíveis ao exercício profissional. Esses saberes mobilizados constituem uma identidade profissional docente.

Ao analisar os relatos dos professores colaboradores, observamos que foram formados em contextos paradigmáticos diversos, o que caracterizou o processo formativo de cada um. No que se refere aos saberes, estes demonstram que possuem uma diversidade de saberes e que estes se mobilizam garantindo, assim, o ser e o estar na profissão docente e na condição de formador de formadores. Outro destaque em relação às narrativas

Pacheco (2002) assegura que ser professor é viver na complexidade, no desafio permanente da melhoria, na multidimensionalidade do agir e pensar, na interrogação constante que a sociedade do conhecimento coloca. Para Hargreaves, (2004) é na sociedade do conhecimento e da informação que nascem novos desafios para a construção da profissionalidade docente, progressivamente, pautada por critérios que, de modo algum, podem ignorar o humano e o profissional.

Desse modo, concebemos professor formador como um profissional oriundo de paradigmas formativos, um docente que tem um conjunto complexo de saberes oriundos das Ciências Humanas, das técnicas, da gestão didático-pedagógica, das Ciências de Referência deles e da pesquisa. Saberes não prescritivos. É um docente que assume uma postura de formador profissional capaz de relacionar, de acompanhar, de orientar e avaliar o profissional em formação. Um professor capaz de compartilhar culturas, situações, contextos diversos, de dialogar e de conviver com as complexidades, os erros e as incertezas. Concordamos com os autores, um profissional que detenha uma metacompetência, a capacidade reflexiva de práticas de formação, portanto é um profissional polivalente. 


\section{Referências}

BOM MEIHY, J.C.S. Manual de História Oral. 4. ed. São Paulo: Loyola, 2002.

BURKE, P. A classificação do conhecimento: Currículos, Bibliotecas e Enciclopédias. In: BURKE, P. Uma história Social do Conhecimento. De Gutenberg a Diderot. Rio de Janeiro: Jorge Zahar, 2003. p. 78-108.

CANDAU, V. M. (Org.). O professor universitário na transição de paradigmas. Araraquara: JM., 1998.

CANDAU, V. M. Políticas públicas e docência na universidade: novas configurações e possíveis alternativas. Revista Portuguesa de Educação, Portugal, v. 16, n. 2, p. 45-68, 2004.

CONTRERAS, D. J. La autonomia Del professorado. Madri: Morata, 1997.

DUBET, F; MARTUCCELLI, D. A l'ecole: sociologie de l'experience scolaire. Paris: Seuil, 1996.

FOUCAULT, M. A arqueologia do saber. Trad. L. F. B. Neves. Rio de Janeiro: Forense Universitária. 1987. (Original publicado em 1969).

GAMBOA, S. S. Teoria e prática: uma relação dinâmica e contraditória. Revista Motrivivência, Universidade Federal de Santa Catarina, Florianópolis, ano 07, n. 8, p. 3145, dez. 1995.

GAUTHIER, C. et al. Por uma teoria da Pedagogia: pesquisas contemporâneas sobre o Saber Docente. ljuí: Unijuí, 1998.

GAUTHIER, C.; MELLOUKI, M'. O professor e seu mandato de mediador, herdeiro, intérprete e crítico. Educ. Soc., Campinas, v. 25, n. 87, p. 537-571, ago. 2004. Disponível em <http://www.scielo.br/scielo.php?script=sci_arttext\&pid=S0101$73302004000200011 \&$ Ing=pt\&nrm=iso>. Acesso em 09 nov. 2020.

GHEDIN, E. Professor Reflexivo: da alienação da técnica à autonomia da crítica. In PIMENTA, S; GHEDIN, E. (Orgs.). Professor reflexivo no Brasil: gênese e crítica de um conceito. São Paulo. Cortez, 2002. p. 129-150.

GIROUX, H. A. Os professores como intelectuais transformadores. In: GIROUX, H. A. Os professores como intelectuais rumo a uma Pedagogia crítica da aprendizagem. Porto Alegre: Artes Médicas, 1997. (cap. 9).

GIROUX, H. A. Los professores como intelctuales. Hacia una Pedagogia crítica Del apresndizaje. Barcelona: Paidós/ MEC, 1990.

GÓMEZ, A. P. A função e a formação do professor/a no ensino para a compreensão: diferentes perspectivas. In: SACRISTÁN, J. G.; GÓMEZ, A. P. Compreender e transformar o ensino. 4. ed. Porto Alegre: Artes Médicas, 1998. p. 353-379. 
HARGREAVES, A. O ensino na sociedade do conhecimento: a educação na era da insegurança. Porto: Porto Editora, 2004.

MORAES, M. C. M.; TORRIGLIA, P. L. Sentidos de ser docente e da construção de seu conhecimento. In: MORAES, M. C. M. (Org.). lluminismo às avessas: produção de conhecimento e políticas de formação docente. Rio de Janeiro: DP\&A, 2003. p. 45-60.

PACHECO, J. A. Políticas curriculares. Porto: Porto Editora, 2002.

PEREIRA, J. E. D. Formação de Professores: pesquisas, representações e poder. 2.ed. Belo Horizonte: Autêntica, 2006.

PERRENOUD, P. Práticas pedagógicas, profissão docente e formação: perspectivas sociológicas. Lisboa: Dom Quixote / Instituto de Inovação Educacional, 1993.

PERRENOUD, P. Ensinar: agir na urgência, decidir na incerteza. Trad. Cláudia Schilling. 2. ed. Porto Alegre: Artmed, 2001. 208p.

PIMENTA, S. G. Formação dos profissionais da Educação - visão crítica e perspectivas de mudança. Educação \& Sociedade, São Paulo, v. 69, p. 4-28, 1999.

PIMENTA, S. G. (org.). Saberes pedagógicos e atividade docente. São Paulo: Cortez, 1999.

PIMENTA, S. G. A Didática como mediação na construção da identidade do professor: uma experiência de ensino e pesquisa. In: ANDRÉ, M.; OLIVEIRA, M. R. (Orgs.). Alternativas do Ensino de Didática. Campinas: Papirus, 1997. p. 37-70.

PIMENTA, S. G. Formação de Professores: identidade e saberes da docência. In: PIMENTA, S. G. Saberes Pedagógicos e Atividade Docente. São Paulo: Cortez, 2002.

RODRIGUES, Â. A formação de Formadores para a Prática na Formação Inicial de professores. Faculdade de Psicologia e Ciência da Educação. Universidade de Lisboa. 2009. Disponível em < http://www.educ.fc.ul.pt/recentes/mpfip/pdfs/arodrigues.pdf >. Acesso em 09 de novembro 2020.

SACRISTÁN, J. G. O Currículo: uma reflexão sobre a prática. Porto Alegre: Artes Médicas, 1998.

SANTOS, L. L C. P. Formação de professores e qualidade do ensino. In: SANTOS, L. L. C. P. Escola Básica. Campinas: Papirus, 1992. p. 137-146. Coletânea CBE.

SAVIANI, D. Os saberes implicados na formação do educador. In: BICUDO, M. A.; SILVA JUNIOR, C. A. (Orgs.). Formação do Educador: dever do Estado, tarefa da Universidade. São Paulo: Unesp, 1996. p.39-50.

SHIROMA, O. O eufemismo da profissionalização. In: MORAES, M. C. M. (Org.). Iluminismo às avessas: produção de conhecimento e políticas de formação docente. Rio de Janeiro: DP\&A, 2003. p. 61-79. 
SCHÖN, D. A. Educando o Profissional Reflexivo: um novo design para o ensino e a aprendizagem. Porto Alegre: Artmed, 2000.

SILVA, M. H. G. F. Saber docente: Contingências culturais, experenciais, psico-sociais e formação. In: Anais da 20a Anped, 1997 (disq.).

TARDIF, M. Saberes docentes e formação profissional. 2. ed. Petrópolis: Vozes, 2000.

TARDIF, M. Saberes profissionais dos professores e conhecimento universitário. Rio de Janeiro: PUC, 1999.

TARDIF, M.; LESSARD. C. Saberes profissionais dos professores e conhecimentos universitários - elementos para uma epistemologia da prática profissional dos professores e suas conseqüências em relação à formação para o magistério. Revista Brasileira de Educação, ANPED, São Paulo, n. 13, p.5-24, jan./abr. 2000.

TARDIF, M.; GAUTHIER, C. O saber profissional dos professores - fundamentos e epistemologia. In: SEMINÁRIO DE PESQUISA SOBRE O SABER DOCENTE, 1996, Fortaleza. Anais. Fortaleza: UFCE, 1996. (mimeo).

TARDIF, M.; LESSARD, C.; LAHAYE, L. Os professores face ao saber - esboço de uma problemática do saber docente. Teoria \& Educação, Porto Alegre, n. 4, 1991.

VEIGA, I. P. A. A Prática Pedagógica do Professor de Didática. Campinas, SP: Papirus, 1989.

ZEICHNER, K. El maestro como profesional reflexivo. Cuadernos de Pedagogía, 1992. n.220, p.44-49. 